\title{
Optimization of multi- period empty container repositioning and renting in CHINA RAILWAY Express based on container sharing strategy
}

\author{
Yinying Tang ${ }^{1,2,3}$, Si Chen ${ }^{1,2,3^{*}}$ (D), Yuan Feng ${ }^{1,2,3}$ and Xinglong Zhu ${ }^{1,2,3}$
}

\begin{abstract}
Background: With the steady growth of trade between China and Europe, the number of trains in CHINA RAILWAY Express has steadily increased under the Belt and Road Initiative. By the end of 2019, more than 21,000 trains have been operated. However, in the development of CHINA RAILWAY Express, the cost of empty container transportation and leasing remains high. So, it is necessary to put forward the strategy of container sharing.

Aim: Through the optimization of empty container transfer and rent under container sharing, this study aim to reduce the operation cost and put forward the strategy of container sharing.

Method: Considering the dynamic characteristics of empty container transportation in reality, this paper constructs a multi-period empty container transportation optimization model with the lowest total cost and the stability of the network, combining with the container sharing strategy. Lyapunov optimization method is used to transform the complex problem into a single period optimization problem, and then genetic algorithm is used to solve the model.

Result: Based on the analysis of 13 existing regular train companies, the results show that the model can effectively improve the utilization rate of containers and reduce the cost in the decision-making period. Based on the results and parameters analysis, some suggestions are put forward to optimize the empty container sharing and effectively realize of container sharing.
\end{abstract}

Keywords: CHINA RAILWAY Express, Container sharing, Dynamic optimization, Empty container transportation

\section{Introduction}

With the steady growth of trade between China and Europe, the willingness of China to strengthen cooperation with Europe has risen. In December 2020, the leaders of China and the EU jointly announced the completion of the China-EU Comprehensive Agreement on Investment (CAI) as scheduled. This represents another positive step

\footnotetext{
* Correspondence: chensi@swjtu.edu.cn

'School of Transportation and Logistics, Southwest Jiaotong University, No.

111, North Section 1, Second Ring Road, Chengdu 610031, China

${ }^{2}$ National Engineering Laboratory of Integrated Transportation Big Data

Application Technology, Chengdu 610031, China

Full list of author information is available at the end of the article
}

forward in China-EU relations, which will bring greater two-way market openness and fairer conditions of competition to both sides. Under the background, the Belt and Road Initiative was proposed, and the China Railway Express, namely the international container train running between China and Europe as well as countries along the Belt and Road, began to operate. By the end of 2019, China Railway Express has accumulated 21,225 trains, both the number of trains running, the number of trains running in cities, the number of round-trip trains and the heavy container rate have all increased significantly. 
However, due to the unbalanced economic development and the great difference in the distribution of goods, the container flow is unbalanced in space and time. The most direct indication of this imbalance is the trade deficit between China and the EU. According to Chinese customs data, in 2020, China's exports to the EU amounted to US $\$ 39.98$ billion, while its imports from the EU amounted to US \$258.55 million. China's trade surplus with the EU was US $\$ 132.43$ billion, This is also one of the reasons why the number of return trains between China and Europe is lower than the number of trips. And many products transported by China Railway Express are seasonal, which brings seasonal fluctuations in freight volume. In order to better solve the unbalanced freight demand, the railway container transport enterprises must carry out reasonable transportation and distribution of empty containers. In the early stage of market cultivation, some cities that launched freight train services were eager to attract goods in order to enhance the scale of development bank and improve the position of hub. Due to the limited market, in order to reduce the empty container rate and attract goods sources, local governments increased the intensity of subsidies. In order to maintain the reputation of the operating company and the ability to collect goods, and meet the requirements of filling 4140 - $\mathrm{ft}$ containers to deliver goods, so at the initial stage, even if there is no full load, companies insist on sending trains, which produces empty container transportation. Therefore, empty container transportation is one of the phenomena caused by the government subsidies which are anti-market behavior and eager to improve the operation scale of China Railway Express. only a few cities have sufficient return cargo sources, and most of the cities have the problem of unbalanced number of return trains, which leads to a considerable number of empty containers unable to be transported back after unloading abroad, and the problem of empty container transportation is serious. The container resources of each train company can only be used by itself, but they cannot make full use of the existing container resources, and the overall cost of obtaining empty containers is still high.

The above problems increase the operating cost of China Railway Express and restricts the further development of China Railway Express. In order to effectively alleviate this problem, the China Railway Express transportation coordination committee proposed to build a container sharing platform. Under the guidance of this policy, as a key point to reduce the operation cost of China Railway Express, how to optimize the overall empty container acquisition of China Railway Express, effectively realize the container sharing platform, improve the utilization rate of container resources, and help China Railway Express to develop in high quality and quantity has become an urgent problem.

Therefore, in order to reduce the cost of empty container acquisition and further improve the market competitiveness, this paper analyzes the flow process of China Railway Express container, and establishes a model of empty container transfer and leasing based on container sharing. The other parts of this paper are as follows: the second part reviews the relevant research of empty container transportation container sharing and China Railway Express; the third part establishes the empty container rent transfer model of China Railway Express based on container sharing, and puts forward the corresponding algorithm. In the fourth part, the model is validated and analyzed with 13 companies as examples. The fifth part is the sensitivity analysis of different factors. The last part is the conclusion of this paper.

\section{Literature review}

In the aspect of empty container transportation, in the earliest period of research on empty container transportation, White and Bomberault [1] first studied the problem of Railway Empty Container transportation, proposed the optimization model and designed the induced network flow algorithm for the first time. Misra [2] regards the empty container transportation of railway containers as a transportation problem, and establishes a linear programming model with the objective of minimizing the cost of empty container transportation and uses the simplex method to solve it. With the deepening of research, scholars gradually consider a variety of influencing factors. Song and Dong [3] established a model of empty container transportation by sea when considering the flexible destination port. Crainic et al. [4] took the inland empty container transportation between port, station and customer as the research object, and established the dynamic and stochastic optimization model of empty container transportation. Cheung and Chen [5] considered the dynamics and randomness of empty container transportation, constructed a two-stage stochastic network optimization model, and used the stochastic quasi gradient method and the stochastic mixed approximation method to solve the model. Choong et al. [6] studied the problem of empty container transportation in the context of multimodal transport, and established an integer programming model based on the premise of meeting the demand of heavy containers. Shen and Khoong [7] established an optimization model of empty container transportation for liner companies with the decision variables of the number of containers rented and the number of containers returned. Shi [8] focused on the inland container transportation system, combined with the empty container transportation and leasing strategy, established a mathematical model, and used simulation for case analysis. Moon et al. [9] constructed the model of empty container transportation by sea considering the 
leasing and purchasing factors of empty containers. Chen and Wang [10] considered that the supply and demand of empty containers in all ports are fuzzy random numbers, combined with port empty container dispatching and leasing, established a multi-stage decision-making optimization model of port empty container inventory, and analyzed the impact of the limited number of empty container leasing on the optimal empty container patronage. An et al. [11] incorporate the specific natures of inland waterway containers transportation and formulate the inland waterway system containers transportation into a mathematic model, a combined algorithm with genetic algorithm (GA) and Integer programming (IP) calculations are designed to solve this program. Further, a network of Yangtze River ports is studied. Xing et al. [12] considered the replacement of foldable containers, and assumed that standard containers can be obtained by leasing, while foldable containers can be obtained by purchasing. Through three cases: only using standard containers, only using foldable containers, and using standard containers and foldable containers for modeling and analysis, the results showed that only under specific conditions to purchase folding containers. In summary, the existing research on empty container transportation is relatively sufficient, and there are some achievements in all aspects. The model and solution algorithm can provide a strong reference for the research of this paper. However, when it comes to container leasing, most of the existing literature focuses on shipping; Secondly, most of the literature pay more attention to the container leasing strategy, and the container return strategy is a little insufficient. This part is very important for the China Railway Express companies.

In terms of container sharing, Damas [13] once proposed container pool, the prototype of container sharing, and thought that container pool can fully reduce the cost. Sterzik [14] clearly put forward the concept of container sharing based on the example of inland transportation. Inland transportation operators can share real-time information and stacking information of containers, and can exchange and use containers. Cao [15] proposed that liner companies usually form a strategic alliance in the form of resource sharing. In the alliance, they can also borrow the containers of other liner companies in the alliance, and then set up a mathematical model with the goal of minimizing the cost of obtaining empty containers. Xing [16] based on the empty container mutual leasing strategy, established the empty container dynamic dispatching optimization model for each segment of the liner route, and designed a dynamic algorithm to solve the problem. Wang and Chen [17] considered the container cooperation between different shipping companies in multiple ports, and introduced the idea of port empty container matching. Aiming at the minimum expected total cost in multiple stages, he established an empty container dispatching optimization model for multiple port and multi shipping companies. Zhang et al. [18] based on the actual business process, established the empty container transportation optimization model, designed two simulation cases of liner company's alliance mode and non-alliance mode. In summary, the existing research on container sharing has some achievements in policy and operation. A large number of studies show that container sharing can indeed reduce the cost and increase the profits of container operating enterprises, which can provide some reference for this paper in how to model. However, most of the studies focus on shipping companies or inland shipping companies, and there is still a lack of relevant research on China Railway Express with multi stakeholder participation.

In the relevant research of China Railway Express, $\mathrm{Li}$ [19] divided the life cycle of China Railway Express based on the product life cycle theory, summarized the development situation of China Railway Express, and proposed the development strategy of China Railway Express from the perspective of transportation organization and goods source organization. Xing [20] analyzed the macro and micro marketing environment of "HarbinEurope" train with modern marketing theory, and subdivided the freight market with STP theory, and put forward the 'Harbin Europe' marketing strategy. Vinokurov [21] took Asia- Europe Container Transportation as the research object, established the analysis indicators in terms of total economic and trade volume, restrictions, railway freight rates, potential, etc., and put forward the commodity catalogue with the development prospect of Asia Europe Container. In terms of quantitative research, Du and Shi [22] studied the dynamic game relationship between enterprises and governments related to China Railway Express, and gave the optimal subsidy amount between enterprises and governments under the maximum social benefit. Chen et al. [23] compared the advantages and competition of land and sea transportation of containers across Asia and Europe, considered the freight and time constraints with the lowest total cost as the goal, constructed a mathematical optimization model, and used deterrence theory to analyze the competitiveness of the two. Jiang et al. [24] focused on the composition of freight cost of China Railway Express, compared and analyzed 5 companies and maritime transport, constructed a two-logit model to evaluate the selection behavior of shippers for two modes of transport, and concluded that China Railway Express are more attractive to it products. Both the qualitative research on policy suggestions and other aspects of China Railway Express have fully analyzed the problems of China Railway Express in all aspects, especially for the empty container transportation cost due to the shortage of return goods, and also put forward targeted suggestions and countermeasures. However, most of the quantitative research focus on the operation scheme, hub location, route selection and other aspects. 
Although there are a few studies on the empty containers of China Railway Express, they ignore the factors such as container source, rental return and lack of thinking on container sharing strategy.

\section{Optimization model of empty container transfer and rent of China railway express based on container sharing}

In the daily transportation organization process of China Railway Express, each train needs to carry $4140-\mathrm{ft}$ containers. Therefore, when a company's empty containers at a certain station are not enough to operate the train, it can transfer its own containers or those of other train companies at the adjacent stations, or lease the containers of CHINA RAILWAY CONTAINER (CRCT) or CHINA COSCO SHIPPING GROUP (COSCO). Therefore, this paper builds a mathematical model for the above-mentioned transportation and leasing strategies. The following assumptions are made:

(1) It is assumed that each train company is a rational actor, and there is no malicious occupation of empty containers.

(2) According to the operation of China Railway Express, the container type is uniformly designated as $40-\mathrm{ft}$ general standard container.

(3) The cost of empty container transportation and rental between stations are known.

(4) The transport demand between stations is known.

(5) Each company has a certain number of empty containers in each station.

(6) No consideration will be given to damage or scrapping of containers.

(7) The container of the leasing container company rents the container at the nearest leasing point from the station, and there is no limit on the quantity, and it needs to be returned at the specified time. If the return exceeds the specified time, it needs to pay the overdue fee.

(8) Set the single cycle of the decision-making period as 1 week.

(9) The empty container transportation system of China Railway Express, is divided into Chinese and European terminal transportation systems, that is, the starting point and destination of one-time empty container transportation are always in one system, and can be completed within 1 week.

(10)Only one mode of transportation is considered in the model, i.e. only empty containers are used for railway transportation between stations.

The definition of relevant parameters and variables is shown in Table 1.

\subsection{Model construction}

\section{(1) Objective function.}

In this paper, the objective function is established to minimize the total cost of empty container acquisition in the decision-making period.

Among them, empty container transportation cost and transaction cost ( $0.3 \%$ of transportation cost), the transportation distance, the main factor causing the transaction cost in this paper, is considered, so $0.3 \%$ of the transportation cost is taken as the transaction cost.:

$$
\mathrm{Z}_{1}=\sum_{\mathrm{t} \in \mathrm{T}} \sum_{\mathrm{k} \in \mathrm{I}_{1}} \sum_{\mathrm{g} \in \mathrm{I}_{1}} \sum_{\mathrm{i} \in \mathrm{I}} \sum_{\mathrm{j} \in \mathrm{I}} \mathrm{x}_{\mathrm{ijkg}}^{\mathrm{t}}\left(\mathrm{c}_{\mathrm{ij}}+3 \% \mathrm{c}_{\mathrm{ij}}\right) \text {. }
$$

Rental cost. It is composed of lease fee, transportation fee incurred in the process of lease return and overdue fee:

$$
\begin{aligned}
& \mathrm{Z}_{2}=\sum_{\mathrm{t} \mathrm{T}} \sum_{\mathrm{kE},} \sum_{\mathrm{ieI}}\left(\mathrm{cy}+\mathrm{cy}_{\mathrm{i}}^{\mathrm{trans}}\right) \cdot \mathrm{ly}_{\mathrm{ik}}^{\mathrm{t}}+\left(\mathrm{cj}+\mathrm{c}_{\mathrm{i}}^{\mathrm{trans}}\right) \cdot \mathrm{l}_{\mathrm{j}}^{\mathrm{t}} \\
& \left.+\mathrm{cj}_{\mathrm{i}}^{\text {trans }} \cdot \mathrm{hj}_{\mathrm{ik}}^{\mathrm{t}}+\mathrm{cy}_{\mathrm{i}}^{\text {trans }} \cdot \mathrm{hy}_{\mathrm{ik}}^{\mathrm{t}}+\mathrm{cj}^{\text {outlast }} \cdot \mathrm{hjo}_{\mathrm{ik}}^{\mathrm{t}}+\mathrm{cy}_{\mathrm{i}}^{\text {outlast }} \cdot \mathrm{hyO}_{\mathrm{ik}}^{\mathrm{t}}\right) \text {, }
\end{aligned}
$$

Storage cost:

$$
\mathrm{Z}_{3}=\sum_{\mathrm{t} \in \mathrm{T}} \sum_{\mathrm{k} \in \mathrm{I}_{1}} \sum_{\mathrm{i} \in \mathrm{I}}\left(c_{\mathrm{i}}^{\text {store }} \cdot \mathrm{b}_{\mathrm{ik}}^{\mathrm{t}}\right) .
$$

Therefore, the objective function is:

$$
\operatorname{Min} \mathrm{O}(\mathrm{t})=\mathrm{Z}_{1}+\mathrm{Z}_{2}+\mathrm{Z}_{3} \text {. }
$$

(2) Container quantity conservation constraint: $\quad i \in$ $I, \quad k \in I_{1}, \quad t \in T$

$$
\begin{aligned}
b_{i k}^{t}= & b_{i k}^{t-1}+\sum_{g \in I} \sum_{j \in I} x_{j i k g}^{t}+\sum_{j \in I} d_{j i k}^{t} \\
& +l_{j i k}^{t} \\
& +l_{i k}^{t}-\sum_{j \in I} d_{i j k}^{t}-h j_{i k}^{t}-h y_{i k}^{t}-\sum_{g \in I_{1}} \sum_{j \in I} x_{i j g k}^{t},
\end{aligned}
$$

The constraint represents: At the end of $\mathrm{T}$ period, $\mathrm{K}$ company's container volume at site $\mathrm{I}=$ at the end of last period, $\mathrm{K}$ company's container at the site + transferred empty container + heavy container transported by China Railway Express + leased container - container transported by China Railway Express - returned container transferred empty container.

(3) Return restrictions on containers: $t \in T$ : 
Table 1 Description of parameters and variables

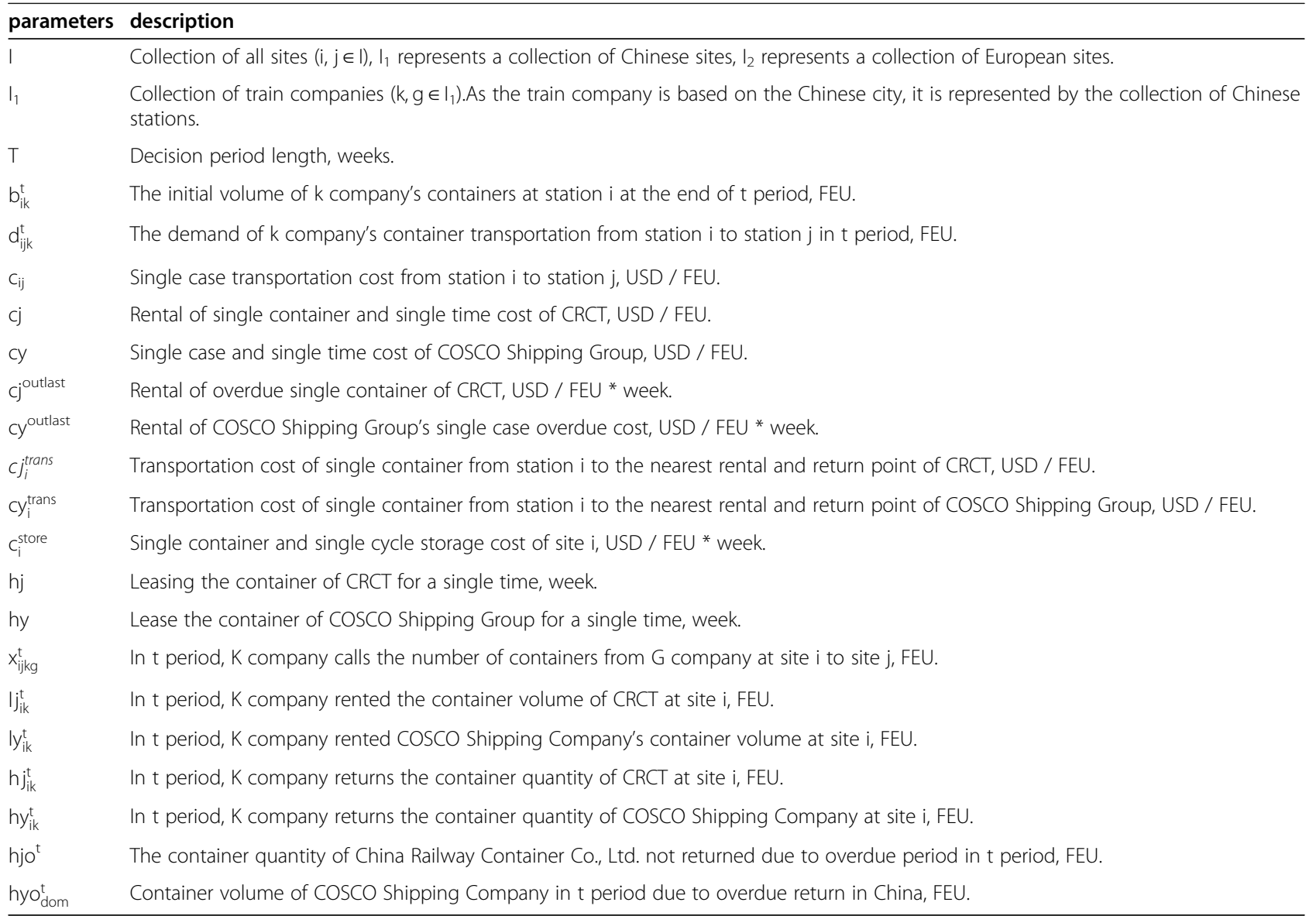

$$
\begin{aligned}
& \operatorname{hyo}_{\mathrm{dom}}^{\mathrm{t}-1}+\sum_{\mathrm{i} \in \mathrm{I}_{2}} \sum_{\mathrm{k} \in \mathrm{I}_{1}} \mathrm{ly}_{\mathrm{ik}}^{\mathrm{t}-\mathrm{hy}} \\
& =\mathrm{hyo}_{\mathrm{dom}}^{\mathrm{t}}+\sum_{\mathrm{i} \in \mathrm{I}_{1}} \sum_{\mathrm{k} \in \mathrm{I}_{1}} \mathrm{hy}_{\mathrm{ik}}^{\mathrm{t}} ; \\
& \text { hyo }_{\mathrm{abr}}^{\mathrm{t}-1}+\sum_{\mathrm{i} \in \mathrm{I}_{1}} \sum_{\mathrm{k} \in \mathrm{I}_{1}} \mathrm{ly}_{\mathrm{ik}}^{\mathrm{t}-\mathrm{hy}} \\
& =\text { hyo }_{\mathrm{abr}}^{\mathrm{t}}+\sum_{\mathrm{i} \in \mathrm{I}_{2}} \sum_{\mathrm{k} \in \mathrm{I}_{1}} \mathrm{hy}_{\mathrm{ik}}^{\mathrm{t}} ; \\
& \text { hjo }^{\mathrm{t}-1}+\sum_{\mathrm{i} \in \mathrm{I}_{1}} \sum_{\mathrm{k} \in \mathrm{I}_{1}} \mathrm{j}_{\mathrm{ik}}^{\mathrm{t}-\mathrm{hj}} \\
& =\text { hjo }^{\mathrm{t}}+\sum_{\mathrm{i} \in \mathrm{I}_{1}} \sum_{\mathrm{k} \in \mathrm{I}_{1}} \mathrm{hj}_{\mathrm{ik}}^{\mathrm{t}} .
\end{aligned}
$$

Equation (3-6) indicates: The sum of the number of COSCO shipping containers not returned in time at the Chinese segment in $\mathrm{T}$ period and the number of COSCO shipping containers returned in $\mathrm{T}$ period is equal to the sum of the number of COSCO shipping containers not returned in time at the Chinese segment in T-1 period and the COSCO shipping containers leased abroad in the t-hy period. Formula (37) and (3-8) mean the same meaning, except that the leasing object becomes COSCO Shipping Container and CRCT's container leased at the European end respectively.
(4) Empty container call out limit: $\quad \mathrm{i} \in \mathrm{I}, \quad \mathrm{k} \in$ $\mathrm{I}_{1}, \quad \mathrm{t} \in \mathrm{T}:$

$$
\sum_{g \in I_{1}} \sum_{j \in I} x_{i j g k}^{t}+h j_{i k}^{t}+h y_{i k}^{t} \leq b_{i k}^{t-1}
$$

The constraint represents: For site I, the sum of the empty containers transferred out and returned by company $\mathrm{K}$ at the site shall not exceed the empty containers at the end of the previous period.

(5) Transport stability of China Railway Express:

$$
\lim _{\mathrm{T} \rightarrow \infty} \frac{1}{\mathrm{~T}} \sum_{\mathrm{t}=1}^{\mathrm{T}} \sum_{\mathrm{i} \in \mathrm{I}} \sum_{\mathrm{k} \in \mathrm{I}_{1}} \mathrm{E}\left(\mathrm{b}_{\mathrm{ik}}^{\mathrm{t}}\right)<\varepsilon
$$

The constraint represents: When the time period tends to infinity, the total amount of container storage, i.e. backlog, is less than, which means a positive number less than infinity. This restriction can improve the utilization 
rate of containers as much as possible and ensure the stability of China Railway Express transportation.

(6) Rent adjustment conditions:

$$
\begin{aligned}
& x_{\mathrm{ijkg}}^{\mathrm{t}}=0\left(\forall \mathrm{i} \in \mathrm{I}_{1}, \forall \mathrm{j} \in \mathrm{I}_{2}\right) \operatorname{or}\left(\forall \mathrm{i} \in \mathrm{I}_{2}, \forall \mathrm{j} \in \mathrm{I}_{1}\right) ; \\
& \mathrm{x}_{\mathrm{ijkg}}^{\mathrm{t}}=0\left(\forall \mathrm{i} \in \mathrm{I}_{1}, \mathrm{k} \neq \mathrm{j}\right) \operatorname{or}\left(\forall \mathrm{i} \in \mathrm{I}_{1} \mathrm{~g} \neq \mathrm{i}\right) ; \\
& \mathrm{lj}_{\mathrm{ik}}^{\mathrm{t}}=0\left(\forall \mathrm{i} \in \mathrm{I}_{1}, \mathrm{k} \neq \mathrm{i}\right) \operatorname{or}\left(\forall \mathrm{i} \in \mathrm{I}_{2}\right) .
\end{aligned}
$$

Equation (3-11) indicates that the empty container transportation only occurs in the same end of the transportation system, otherwise, the empty container transportation volume is 0. Eq. (3-12) indicates that the Chinese station must match with the train company, otherwise the empty container transportation volume is 0 . Equation (3-13) indicates that when leasing the container of CRCT, the station must match with the train company, and the container of CRCT can only be rented at the domestic end, otherwise, the leasing quantity is 0 .

(7) Nonnegative integer constraint:

$\mathrm{x}_{\mathrm{ijkg}}^{\mathrm{t}}, \mathrm{l}_{\mathrm{ik}}^{\mathrm{t}}, \operatorname{ly}_{\mathrm{ik}}^{\mathrm{t}}, \mathrm{b}_{\mathrm{ik}}^{\mathrm{t}}, \mathrm{hy}_{\mathrm{ik}}^{\mathrm{t}}$ are all nonnegative integers.

\subsection{Model solving}

The model for linear integer programming model, and can be dealt with through certain transformation for the transportation problem, the transportation problem has many precise solution, but consider when site populations, accurate algorithm of time will multiply, according to the document conclusion of $\mathrm{Li}$ et al. [25], the article puts forward the genetic algorithm has not only high efficiency, and can get more optimal solution of the problem. Therefore, in order to solve the model more efficiently, this chapter will use the genetic algorithm in the heuristic algorithm to find the optimal solution of the model.

In this chapter, Lyapunov optimization algorithm is used to transform the global optimization problem into a single time optimization problem, and genetic algorithm is used to solve the single time optimization problem.

Lyapunov optimization method consists of two parts: Lyapunov function and Lyapunov penalty drift.

\section{Lyapunov function}

For the model constructed in this chapter, the quadratic Lyapunov function in a cycle can be defined as:

$$
\mathrm{L}=\frac{1}{2}\left(\mathrm{~b}_{\mathrm{ik}}^{\mathrm{t}}\right)^{2},
$$

The eq. (3-14) can be used to measure the empty container backlog of the whole China Railway Express network in the T period.

Next, the change quantity of Lyapunov function in adjacent period is defined as Lyapunov drift:

$$
\Delta(\mathrm{t})=\frac{1}{2}\left(\mathrm{~b}_{\mathrm{ik}}^{\mathrm{t}+1}\right)^{2}-\frac{1}{2}\left(\mathrm{~b}_{\mathrm{ik}}^{\mathrm{t}}\right)^{2},
$$

According to the definition of Lyapunov drift, we can see that it can reflect the case of empty tank backlog. When Lyapunov drift is minimized, the square difference of empty container backlog in the adjacent period is minimized, and the constraint (3-10) is satisfied. Therefore, constraints ((3-10)) can be removed after model transformation.

Then substituting eq. (3-5) into eq. (3-15) can obtain:

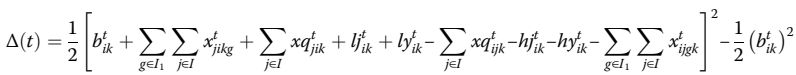

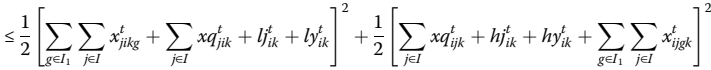

$$
\begin{aligned}
& +b_{i k}^{t}\left[\sum_{j \in I} x q_{j k}^{t}+l_{i k}^{t}+b_{i k}^{t}-\sum_{j \in I} x q_{i j k}^{t}-h_{l k}^{t}-h y_{i k}^{t}-\sum_{g \varepsilon_{1}} \sum_{j \in I} x_{i j k}^{t}\right]
\end{aligned}
$$

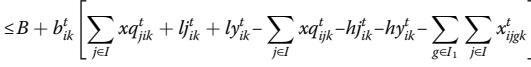

$\mathrm{B}=\frac{1}{2} \mathrm{a}_{\max }^{2}+\frac{1}{2}\left(\mathrm{~b}_{\mathrm{ik}}^{\mathrm{t}}\right)_{\max }^{2}$ is a constant. $\mathrm{a}_{\max }$ represents the maximum transportation demand, i.e. the upper limit of empty containers transferred and leased, and the latter represents the maximum storage, i.e. the upper limit of empty containers transferred.

\section{Lyapunov penalty drift}

Lyapunov penalty drift is a method to optimize the objective function on the premise of ensuring the stability of the network. On the basis of Lyapunov drift, penalty function is added, which is the objective function of optimization, for this model, Lyapunov penalty drift is constructed as follows:

$$
\Delta_{\mathrm{V}}(\mathrm{t})=\Delta(\mathrm{t})+\mathrm{V} \cdot \mathrm{O}(\mathrm{t}),
$$

Where, $\mathrm{O}(\mathrm{t})$ is the objective function of the model in this chapter, i.e. the cost minimum function, and $\mathrm{V}$ is the weight coefficient. By minimizing $\Delta_{\mathrm{v}}(\mathrm{t}), \Delta(\mathrm{t})$ and $\mathrm{O}(\mathrm{t})$ can be optimized simultaneously, which not only satisfies the constraint ((3-10)), but also minimizes the cost of empty container acquisition. The value of $\mathrm{V}$ indicates the importance of empty container acquisition cost. The smaller $\mathrm{V}$ is, the more attention will be paid to the stability of China Railway Express network. On the 


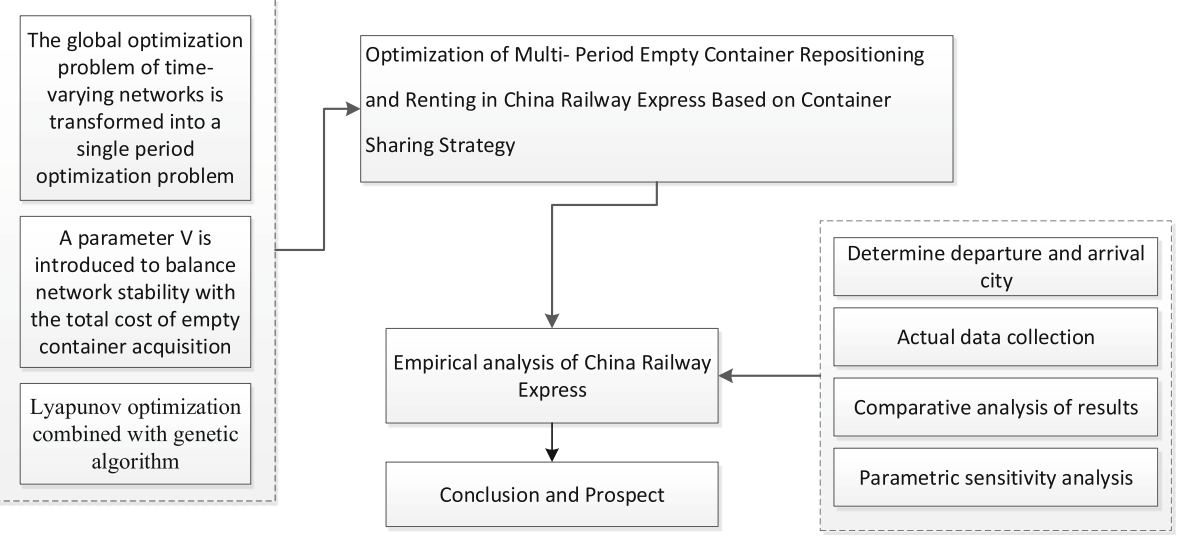

Fig. 1 Solving steps

contrary, the more attention will be paid to empty container acquisition cost.

Substituting eq. (3-16) into eq. (3-17) can obtain:

$$
\Delta_{\mathrm{V}}(\mathrm{t})=\Delta(\mathrm{t})+\mathrm{V} \cdot \mathrm{O}(\mathrm{t}) \leq \mathrm{B}+\Delta_{\mathrm{v}}^{*}(\mathrm{t})
$$

Since B is a constant, we only need to optimize $\Delta_{-} \mathrm{V}^{\wedge *}(\mathrm{t})$ :

$$
\begin{aligned}
& \Delta_{v}^{*}(t)=\sum_{k \in I_{1}} \sum_{i \in I} b_{i k}^{t}\left(\sum_{j=I} x q_{j i k}^{t}+l_{j i k}^{t}+l y_{i k}^{t}-\sum_{j \in I} x q_{i j k}^{t}-h j_{i k}^{t}-h y_{i k}^{t}-\sum_{g \in I_{1}} \sum_{j \in I} x_{i j g k}^{t}\right) \\
& +V\left[\sum_{k \in I_{1}} \sum_{g \in I_{1}} \sum_{i \in I} \sum_{j \in I} x_{i j k g}^{t} c_{i j}+\sum_{k \in I_{1}} \sum_{i \in I}\left(\left(c y+c y_{i}^{\text {trans }}\right) \cdot y_{i k}^{t}+\left(c j+c i_{i}^{\text {trans }}\right) \cdot l_{i k}^{t}\right)\right. \\
& \left.+\sum_{k \in I_{1}} \sum_{i \in I}\left(c_{i}^{\text {trans }} \cdot h j_{i k}^{t}+c y_{i}^{\text {trans }} \cdot h y_{i k}^{t}\right)+\sum_{k \in I_{1}} \sum_{i \in I}\left(c_{i}^{\text {store }} \cdot b_{i k}^{t}\right)\right]
\end{aligned}
$$

\section{Solving steps}

In the last section, Lyapunov optimization algorithm is used to transform the multi period global optimization problem into a single period optimization problem, which greatly reduces the complexity of the model. In this section, genetic algorithm will be used to solve the transformed model, and the solution steps are as follows:

Step 1: input the basic data of the example, including the empty container transportation cost, the initial empty container storage capacity of each station, transportation demand, etc., and set the parameters of genetic algorithm, including the number of iterations, population size, crossover and mutation probability, etc.;

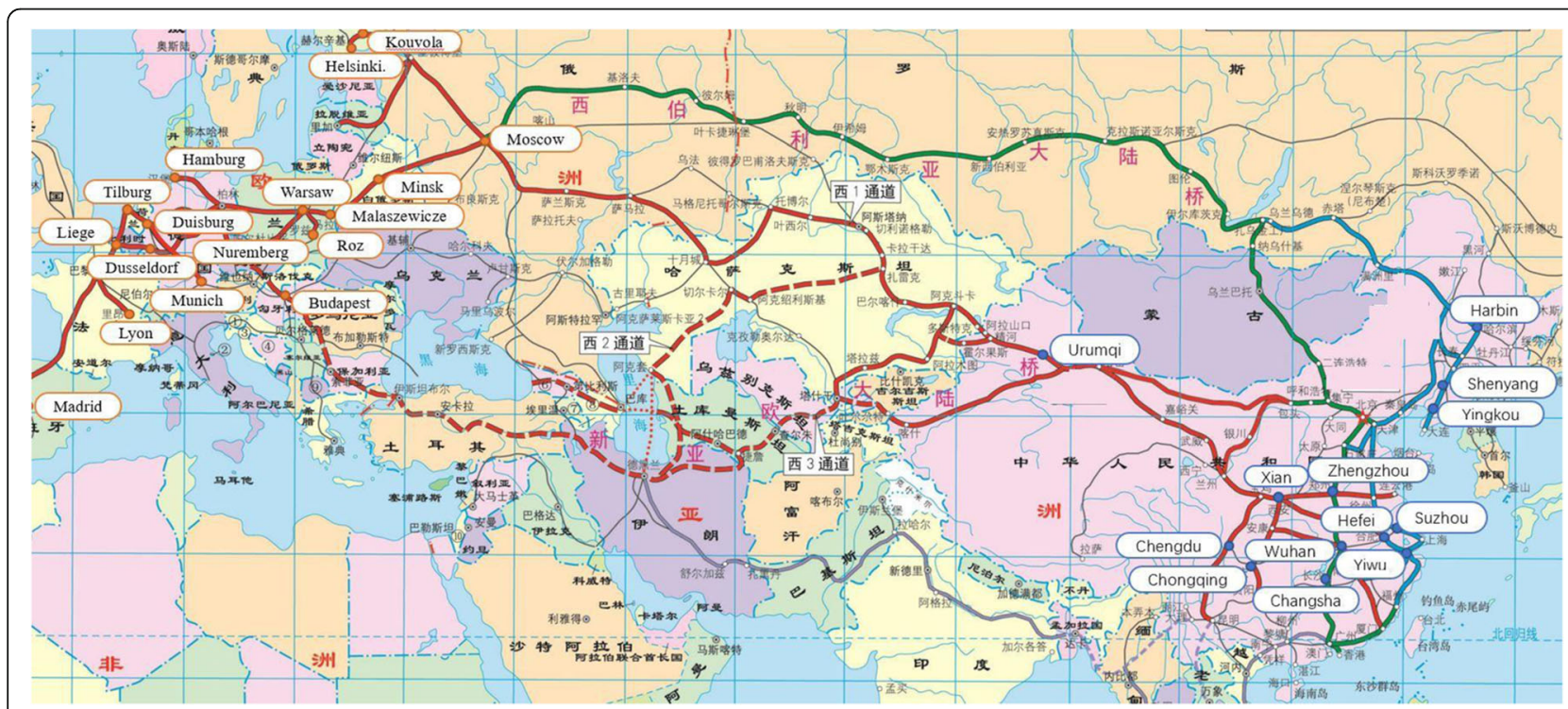

Fig. 2 Roadmap of China Railway Express 
Table 2 Chinese part of empty container transportation scheme (FEU)

\begin{tabular}{|c|c|c|c|c|c|c|c|c|c|c|c|c|c|}
\hline & Chengdu & Chongqing & Zhengzhou & Urumqi & Xi'an & Wuhan & Changsha & Yiwu & Haribin & Shenyang & Yingkou & Suzhou & Hefei \\
\hline Chengdu & 252 & & & & & & & & & & & & \\
\hline Chongqing & & 36 & & & 193 & & & & & & 11 & 5 & \\
\hline Zhengzhou & 199 & 17 & & & & & & & & & 36 & & \\
\hline Urumqi & & & & & & & & 6 & 70 & & & 1 & \\
\hline Xi'an & & 129 & & & & & & & & & & & \\
\hline Wuhan & & 113 & & & & & & & & & & & \\
\hline Changsha & & & & & & & & 13 & 30 & 34 & & & \\
\hline Yiwu & & & & & & & & & & 72 & & & \\
\hline Harbin & & & & & & & & 72 & & & & & \\
\hline \multicolumn{14}{|l|}{ Shenyang } \\
\hline Yingkou & & & & & & & & & 64 & & & & \\
\hline Suzhou & & & & & 6 & & & & & 58 & & & \\
\hline Hefei & & & & & & & & 72 & & & & & \\
\hline
\end{tabular}

Step 2: enter the genetic algorithm calculation of single period optimization model with $\mathrm{T}=1$;

Step 3: according to the coding, initial population generation, selection, crossover, mutation and other methods of genetic algorithm, the optimal rent adjustment scheme with $\mathrm{T}=1$ is obtained after the number of iterations (Fig. 1);

Step 4: let $\mathrm{t}=\mathrm{t}+1$, update the empty container storage capacity of each station at the beginning of $\mathrm{T}$ period according to the optimal rent adjustment scheme of the previous periods;

Step 5: enter the genetic algorithm calculation of single period optimization model in t period, and carry out step 3 to get the optimal rent adjustment scheme in $t$ period;

Step 6: repeat step 4-5 until $\mathrm{t}>\mathrm{T}$. At this time, the optimal rent adjustment scheme in each period constitutes the final rent adjustment scheme.

\section{Example analysis of China railway express} 4.1 Selection of starting and ending cities

According to the current situation of domestic train companies, it can be generally divided into normal operation and abnormal operation. Due to the large number of cities and wide range of China Railway Express, in order to ensure that the research content of this paper is representative, this chapter selects the trains that can be operated normally, i.e., weekly fixed trains as the research object.

To sum up, the starting cities that meet the requirements are: Chengdu, Chongqing, Zhengzhou, Urumqi, Xi'an, Wuhan, Changsha, Yiwu, Harbin, Shenyang, Yingkou port, Suzhou and Hefei. The final cities that meet the conditions are: Roz, Tilburg, Nuremberg, Moscow, Minsk, Duisburg, Hamburg, Malaszewicze, Liege, Madrid, Warsaw, Munich, Kouvola, Budapest, Lyon, Dusseldorf and Helsinki (Fig. 2).

Table 3 European part of empty container transportation scheme (FEU)

\begin{tabular}{|c|c|c|c|c|c|c|c|}
\hline & $\begin{array}{l}\text { Chengdu/ } \\
\text { Lodz }\end{array}$ & $\begin{array}{l}\text { Chengdu/ } \\
\text { Tilburg }\end{array}$ & $\begin{array}{l}\text { Chengdu/ } \\
\text { Nuremberg }\end{array}$ & $\begin{array}{l}\text { Chongqing/ } \\
\text { Duisburg }\end{array}$ & $\begin{array}{l}\text { Chongqing/ } \\
\text { Hamburg }\end{array}$ & $\begin{array}{l}\text { Zhengzhou/ } \\
\text { Hamburg }\end{array}$ & $\begin{array}{l}\text { Zhengzhou/ } \\
\text { Liege }\end{array}$ \\
\hline Chengdu/ Lodz & & & & & & & 82 \\
\hline Chengdu/ Tilburg & & & & & & 126 & \\
\hline \multicolumn{8}{|l|}{$\begin{array}{l}\text { Chengdu/ } \\
\text { Nuremberg }\end{array}$} \\
\hline $\begin{array}{l}\text { Chongqing/ } \\
\text { Duisburg }\end{array}$ & 140 & & 41 & & & & \\
\hline \multicolumn{8}{|l|}{$\begin{array}{l}\text { Chongqing/ } \\
\text { Hamburg }\end{array}$} \\
\hline $\begin{array}{l}\text { Zhengzhou/ } \\
\text { Hamburg }\end{array}$ & & 123 & & & & & \\
\hline $\begin{array}{l}\text { Zhengzhou/ } \\
\text { Liege }\end{array}$ & & & & & & & \\
\hline
\end{tabular}


Table 4 Empty container leasing scheme (FEU)

\begin{tabular}{|c|c|c|c|}
\hline \multirow[t]{2}{*}{ Train company } & \multicolumn{2}{|l|}{ China } & \multirow{2}{*}{$\begin{array}{l}\text { Europe } \\
\text { COsco }\end{array}$} \\
\hline & CRCT & COSCO Shipping & \\
\hline Chengdu International Railway Train Co.,Ltd. & & & 24 \\
\hline Yuxinou (Chongqing) Logistics Co., Ltd. & 74 & & \\
\hline Zhengzhou international land port company & 451 & & \\
\hline Urumqi International Dry Port Co., Ltd. & 205 & & \\
\hline Xi'an international land port multimodal transport Co., Ltd. & 47 & & \\
\hline Wuhan Hanou International Logistics Co., Ltd. & 287 & & \\
\hline Hunan Xiangou Express Logistics Co., Ltd. & 205 & & \\
\hline Yiwu tianmeng Industrial Investment Co., Ltd. & & 1 & \\
\hline Haou International Logistics Co., Ltd. & & & 41 \\
\hline \multicolumn{4}{|l|}{ Shenmanou (Shenyang) International Logistics Co., Ltd. } \\
\hline Liaoning shentie hongyun Logistics Co., Ltd. & 76 & & \\
\hline Suzhou international train freight Co., Ltd. & & 117 & \\
\hline Hefei international inland port development Co., Ltd. & 164 & & \\
\hline
\end{tabular}

\subsection{Solution results}

In this chapter, Python is used to compile the algorithm in Chapter 3 to solve the example whose data is included in Supplementary Material. The optimal rent adjustment decision-making scheme is mainly composed of two parts: "empty container transportation scheme" and "empty container leasing scheme". The specific scheme and related costs will be described in the following.

\section{Empty container transportation plan}

The Chinese transportation plan for the first week is shown in Table 2, and the foreign part transportation plan for the first week is shown in Table 3.

2. Empty container leasing scheme is shown in Table 4.

\subsection{Comparative analysis}

In this section, the acquisition of empty containers under the implementation of container sharing is compared with the acquisition of empty containers under the implementation of container sharing.

In the model in Chapter 2 above, the acquisition cost of empty containers in the second half of 2019 can be obtained by inputting the data of only a train company. 13 freight train companies can be respectively substituted into the model to obtain the acquisition cost of empty containers without sharing. Compare the costs under container sharing with those under unshared and empty container storage, as shown in Table 5 .

According to the comparative analysis of Table 5, the following conclusions can be obtained:

(1) Comparing the two strategies, we can see that container sharing can effectively reduce the cost of empty container acquisition, empty container transportation and empty container storage.

(2) The increase in the rental cost under container sharing indicates that under the container sharing strategy, China Railway Express rent more containers. When more containers are leased, it is easier to negotiate and cooperate with container

Table 5 Comparison of container sharing and non-sharing

\begin{tabular}{llll}
\hline & Container sharing & Container not shared & Reduction rate \\
\hline Total cost (USD) & $97,445,727.35$ & $99,895,784.1$ & $2.45 \%$ \\
Transportation cost (USD) & $63,331,945.35$ & $69,188,951$ & $8.47 \%$ \\
Rental cost (USD) & $21,966,188.3$ & $13,225,838$ & $-66.09 \%$ \\
Storage cost (USD) & $12,147,593.7$ & $17,480,995$ & $30.51 \%$ \\
Average empty container stock per station per week (FEU) & 263.3 & 346.6 & $24.03 \%$ \\
\hline
\end{tabular}




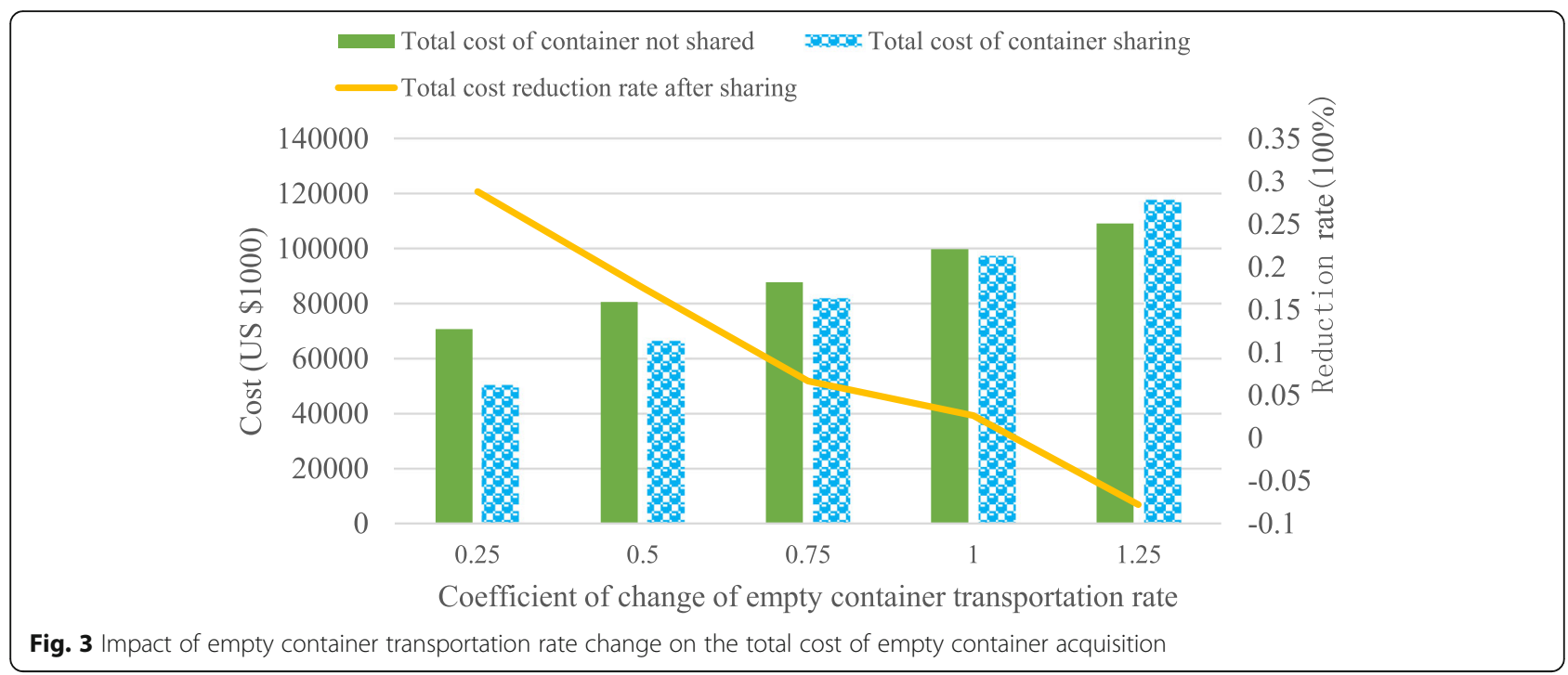

companies, and it is also easier to reduce the rental cost.

(3) Under the condition of container sharing, the average empty container storage per station per week is significantly reduced, which shows that container sharing can significantly reduce the invalid containers.

\section{Sensitivity analysis of related parameters}

When analyzing the sensitivity of some parameters, it is necessary to keep the other parameters unchanged. According to the container transfer process of China Railway Express, factors such as empty container transportation rate and rental container rate have considerable influence on the empty container transfer of China Railway Express. Next, this paper will carry out sensitivity analysis on empty container transportation rate.
With the change of empty container transportation rate, the total cost of empty container acquisition for container sharing or not is shown in Fig. 3, and the cost unit is 1000 USD.

The impact on the average weekly empty container inventory per site is shown in Fig. 4, and the unit of inventory is FEU.

The influence of empty container transportation rate on the proportion of transportation cost in total cost is shown in Fig. 5.

By analyzing Figs. 3, 4, 5, the following conclusions can be drawn:

(1) The lower the empty container transportation rate is, the lower the total cost of empty container acquisition is, and the more cost can be reduced by container sharing. When the empty container transportation rate is $1 / 4$ of the original, the reduction rate of container sharing reaches $28.9 \%$.

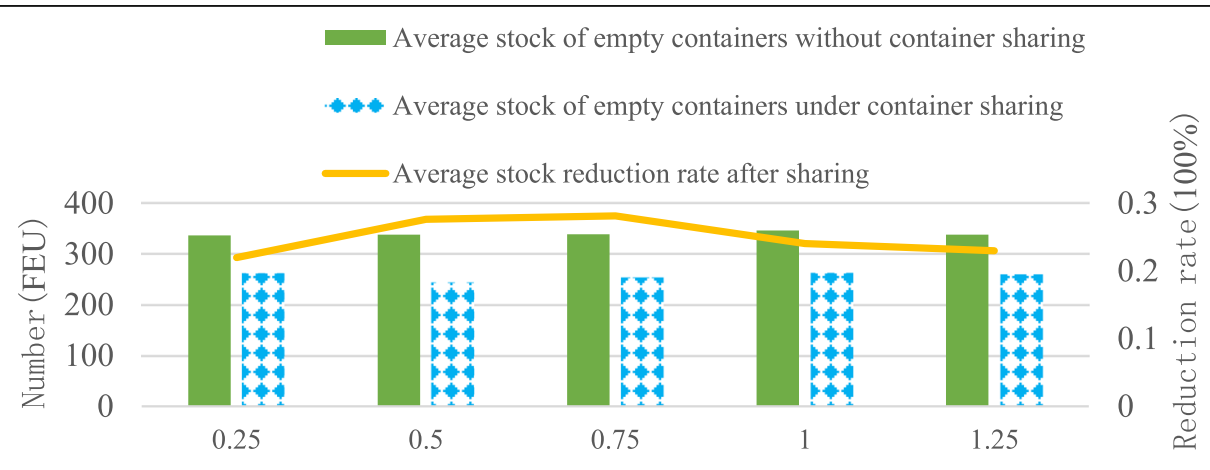

Coefficient of change of empty container transportation rate

Fig. 4 Impact of empty container transportation rate change on the average empty container storage 


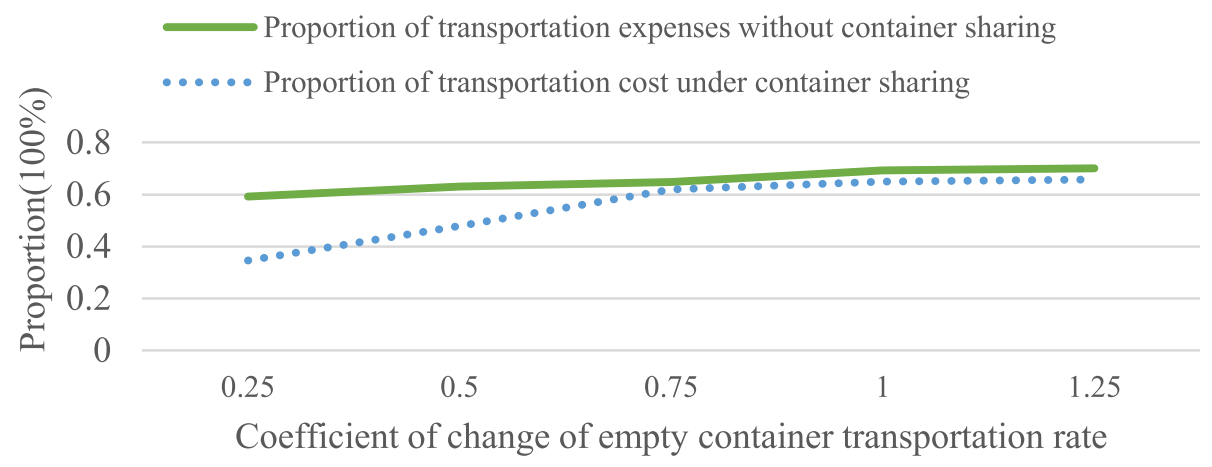

Fig. 5 Impact of empty container transportation rate change on the proportion of transportation cost

However, with the increase of empty container transportation rate, the cost of container sharing is becoming more and more limited.

(2) There is no significant effect of empty container transportation rate on the average storage of empty containers. No matter before or after container sharing, the average storage does not fluctuate significantly. This is because after the model transformation, the minimum cost of obtaining empty containers and the stability of China Railway Express are guaranteed.

(3) No matter before or after container sharing, the increase of empty container transportation rate will lead to the increase of the proportion of empty container transportation cost in the total cost.

\section{Conclusion}

In this paper, considering the container sharing strategy, a dynamic empty container acquisition model with multi stations and multi time periods is proposed. Considering all kinds of factors, the model obtains the empty container transportation volume and different types of rental volume between stations in the decision-making period of each train company, forms a complete and determined empty container acquisition scheme, and provides reference for the decision makers of the train company to make plans.

Through the example of 13 train companies, it is concluded that the total cost of empty container acquisition under the strategy of container sharing is lower than the total cost of empty container acquisition under the condition of container not sharing, and the container stock is significantly reduced.

At present, under the circumstance that container sharing is not implemented on China-Europe freight trains, once a freight train company at a certain station has the demand for empty containers, and its own empty containers cannot arrive at the station in time, the only way to meet the demand is to rent containers. Under container sharing, the freight train company can transfer the empty containers of other freight train companies at the station or adjacent stations, which can improve the utilization rate of containers.

Based on the results of the above comparative analysis and the sensitivity analysis of relevant parameters, this paper puts forward some qualitative Suggestions on the optimization of empty container of China Railway Express.

(1) Coordinate the empty container transport rate with the empty container carrier. After the implementation of container sharing, the China Railway Express is easier to negotiate with European carriers. Reducing the empty container transport rate to an ideal level will effectively reduce the acquisition cost of empty container.

(2) Establish a good cooperation mechanism with the container leasing companies. Since a large number of containers are rented every year, China Railway Express can cooperate with container leasing companies to launch various container leasing products, which can provide China Railway Express with more product choices and reduce the cost of empty container leasing.

(3) Reasonably increase the quantity of containers provided by the freight train and encourage shippers to prepare their own containers. First of all, the increase of the number of containers helps to reduce the acquisition cost of empty containers. However, the purchase of a large number of containers will lead to financial pressure in a short time. Therefore, it can be considered that purchase containers in stages. Second, measures could be introduced to encourage shippers to bring their own empty containers.

Abbreviations

CRCT: China railway container; COSCO: China cosco shipping group 


\section{Supplementary Information}

The online version contains supplementary material available at https://doi. org/10.1186/s12544-021-00498-y.

\section{Additional file 1.}

\section{Acknowledgements}

Not applicable.

\section{Authors' contributions}

The author(s) read and approved the final manuscript.

\section{Funding}

This research was supported by the projects of science and technology research and development plan of China Railway Corporation (grant number P2018X003), Ministry of Education Humanities and Social Sciences project (grant number 16XJCZH001).

\section{Availability of data and materials}

All data generated or analysed during this study are included in this published article and its supplementary information files.

\section{Declarations}

\section{Competing interests}

The authors declare that they have no competing interests

\section{Author details}

'School of Transportation and Logistics, Southwest Jiaotong University, No. 111, North Section 1, Second Ring Road, Chengdu 610031, China. ${ }^{2}$ National Engineering Laboratory of Integrated Transportation Big Data Application Technology, Chengdu 610031, China. ${ }^{3}$ National united Engineering Laboratory of Integrated and Intelligent Transportation, Chengdu 610031, China.

Received: 16 November 2020 Accepted: 25 June 2021

Published online: 27 July 2021

\section{References}

1. White, W. W., \& Bomberault, A. M. (1969). A network algorithm for empty freight car allocation. IBM Syst J, 8(2), 147-169. https://doi.org/10.1147/sj.82. 0147.

2. Misra, S. C. (1972). Linear programming of empty wagon disposition. Rail Internet, 7(3), 151-158.

3. Song, D. P., \& Dong, J. X. (2008). Effectiveness of an empty containe reposition policy with flexible destination ports. Transp Policy, 18(1), 92-101.

4. Crainic, T. G., Gendreau, M., \& Dejax, P. (1993). Dynamic and stochastic models for the allocation of empty containers. Oper Res, 41(1), 102-126. https://doi.org/10.1287/opre.41.1.102.

5. Cheung, R. K., \& Chen, C. Y. (1998). A two-stage stochastic network model and solution methods for the dynamic empty container allocation problem. Transp Sci, 32(2), 142-162. https://doi.org/10.1287/trsc.32.2.142.

6. Choong, S. T., Cole, M. H., \& Kutanoglu, E. (2002). Empty container management for intermoddal transportation networks. Transportation Research Part E: Logistics \& Transportation Review, 38(6), 423-438. https://doi. org/10.1016/S1366-5545(02)00018-2

7. Shen, W. S., \& Khoong, C. M. (1995). A DSS for empty container distribution planning. Decision Support System, 15(1), 75-82. https://doi.org/10.1016/01 67-9236(94)00037-S

8. Shi, X. (2002). Distribution strategy and leasing strategy in the environment of inland empty container transportation. Journal of Traffic and Transportation Engineering, 2, 114-119.

9. Moon, I. K., Ngoc, A. D. D., \& Hur, Y. S. (2010). Positioning empty containers among multiple ports with leasing and purchasing considerations. OR Spectr, 32(3), 765-786. https://doi.org/10.1007/s00291-010-0197-0.

10. Chen, F. Y., \& Wang, C. X. (2013). Multi-stage optimization decision for empty container inventory under fuzzy random condition. Journal of Shanghai Jiao Tong University, 47(02), 312-316.
11. An, F., Hu, H., \& Xie, C. (2015). Service network design in inland waterway liner transportation with empty container repositioning. Eur Transp Res Rev, 7(2), 1-11.

12. Xing, L., Yang, Z. H., Xu, Q., \& Jin, Z. H. (2019). Optimizing empty container dispatching of China railway express under sea-land intermodal transport. Journal of Dalian Maritime University., 45(02), 1-8.

13. Damas, P. (1995). Box matchmakers. Containerisation International, 28(7), $71-$ 73.

14. Sterzik, S. (2013). Concepts, mechanisms, and algorithms to measure the potential of container sharing in seaport hinterland transportation. PhD, University of Bremen.

15. Cao, X. F. (2015). Optimization of empty container allocation by sea transportation based on resources sharing in liner operators. China: MS. Dalian Maritime University.

16. Xing, Y. W., Yang, H. L., \& Chu, F. F. (2016). Empty container reposition in liner alliance based on mutually renting strategy. Journal of Dalian Maritime University, 42(01), 101-106.

17. Wang, C. X., \& Chen, F. Y. (2016). Optimal empty container reposition with collaboration among shipping companies based on multiple ports. Journal of Systems and Management, 25(03), 539-545.

18. Zhang, H. Z., Lu, L. H., \& Wang, X. F. (2019). Profits comparison between alliance mode and non-alliance mode of empty containers repositioning of liner companies. Systems Science and Control Engineering, 7(01), 125-132. https://doi.org/10.1080/21642583.2019.1585302.

19. Li, X.H. (2018). Study on Strategies of Improving CHINA RAILWAY Express Based on Product Life Cycle Theory. ECED 2018, Hangzhou, China. 363-367.

20. Xing, R. (2017). Research on marketing strategy for Harbin-Europe block train of HAO international logistics CO.LTD. MS. Jilin University.

21. Vinokurov, T. (2018). The belt and road initiative and the transit countries: An economic assessment of land transport corridors. Area Development and Policy, 3(1), 93-113. https://doi.org/10.1080/23792949.2017.1385406.

22. Du, Q., \& Shi, X. L. (2017). Et al. a study on the government subsidies for CR express based on dynamic games of incomplete information. Period Polytech Transp Eng, 45(3), 162-167. https://doi.org/10.3311/PPtr.10743.

23. Chen, X., et al. (2017). Game-theoretic comparison approach for intercontinental container transportation: acase between China and Europe with the B\&R initiative. Journal of Advanced Transportation, 2017(128372), 15. https://doi.org/10.1155/2017/3128372.

24. Jiang, Y. L., et al. (2018). Hinterland patterns of China railway (CR) express in China under the belt and road initiative: A preliminary analysis. Transportation Research Part E: Logistics and Transportation Review, 119, 189201. https://doi.org/10.1016/j.tre.2018.10.002.

25. Li, L., Zhang, H., Duan, G. et.al. (2011) Genetic algorithm for railway container empty transportation problem. Journal of Railway Science and Engineering, 8(03):110-115.

\section{Publisher's Note}

Springer Nature remains neutral with regard to jurisdictional claims in published maps and institutional affiliations.

\section{Submit your manuscript to a SpringerOpen ${ }^{\circ}$ journal and benefit from:}

- Convenient online submission

- Rigorous peer review

- Open access: articles freely available online

High visibility within the field

- Retaining the copyright to your article

Submit your next manuscript at $\boldsymbol{\nabla}$ springeropen.com 